\title{
Development of New Catalytic Material for Accurate Detection of Biological Biomarkers Related to Most Common Non-Communicable Diseases ${ }^{\dagger}$
}

\author{
Ana Morais ${ }^{1,2}$, Patrícia Rijo ${ }^{1,3}$ and Marisa Nicolai ${ }^{1, *}$ \\ 1 CBIOS-Research Centre for Biosciences \& Health Technologies, Universidade Lusófona, Campo Grande 376, \\ 1749-024 Lisbon, Portugal; ana.nunes@edu.uah.es (A.M.); patricia.rijo@ulusofona.pt (P.R.) \\ 2 Department of Biomedical Sciences, Faculty of Pharmacy, University of Alcalá, Ctra. A2, \\ Km 33.600-Campus Universitario, 28871 Alcalá de Henares, Spain \\ 3 iMed.ULisboa-Research Institute for Medicines and Pharmaceutical Sciences, \\ Universidade de Lisboa-Faculdade de Farmácia, Av. Prof. Gama Pinto, 1649-003 Lisbon, Portugal \\ * Correspondence: marisa.nicolai@ulusofona.pt \\ † Presented at the 1st International Electronic Conference on Biosensors, 2-17 November 2020; \\ Available online: https://iecb2020.sciforum.net/.
}

Received: date; Accepted: date; Published: date

\begin{abstract}
Presently, long-lasting health disorders represent a significant health problem in developing countries. Further, epidemiological trends associated with lifestyle habits, suggests that chronic conditions trend not to slow down all over the world. Hence, reliable analytical techniques to manage chronic health conditions like diabetes-mellitus, cardiovascular diseases, neurodegenerative diseases, among other noncommunicable diseases (NCD), is of paramount importance [1].
\end{abstract}

Keywords: non-communicable diseases; electrochemical sensors; silver nanoparticles; eco-friendly synthesis; Plecthrantus genus

Electrochemical biosensor is a pivotal technique for low analyte concentration detection, aiming for a swift and accurate diagnosis/therapy, to deal with the various health conditions. Though, the performance of electrobiosensors heavily depends on the catalytic activity of the material used as biosensor transducer. As a result, nanomaterials are widely used on the electrode surface owing to their unique physicochemical characteristics, like the high surface area to volume ratio, which renders their convenient features for biosensing heterogeneous catalysts [2].

Nowadays, silver nanoparticles (AgNPs) are used in numerous biomedical applications, such as therapeutic purposes or as catalytic material in the electrochemical analysis. Notwithstanding AgNP's health benefits impact, conventional methods used in their synthesis, are far from healthy, with scientific researchers pursuit for eco-friendly alternatives without health-hazardous chemicals [3].

One of the most used alternatives is plant-assisted synthesis, where, phytochemicals of the genus Lamiaceae Plectranthus proving to be a remarkable reducing and stabilizing agent of well-dispersed metal nanoparticles [4].

Aim of the current study is the design of a skilled approach for the provision of Plectranthus-assisted AgNPs, pointing their application as high-performance catalytic material in a sensitive biosensor for NCD.

\section{References}

1. Morais, A.L.; Rijo, P.; Hernán, M.B.B.B.; Nicolai, M. Biomolecules and Electrochemical Tools in Chronic NonCommunicable Disease Surveillance: A Systematic Review. Biosensors 2020, 10, 121, doi:10.3390/bios10090121.

2. Morais, A.; Salgado, J.; Šljukić, B.; Santos, D.M.F.; Sequeira, C. Electrochemical behaviour of carbon supported Pt electrocatalysts for $\mathrm{H} 2 \mathrm{O} 2$ reduction. Int. J. Hydrog. Energy 2012, 37, 14143-14151, doi:10.1016/j.ijhydene.2012.07.092. 
3. Khan, S.U.; Saleh, T.A.; Wahab, A.; Khan, M.H.U.; Khan, D.; Khan, W.U.; Rahim, A.; Kamal, S.; Khan, F.U.; Fahad, S. Nanosilver: New ageless and versatile biomedical therapeutic scaffold. Int. J. Nanomed. 2018, 13, 733-762, doi:10.2147/ijn.s153167.

4. Zheng, Y.; Huang, Y.; Shi, H.; Fu, L. Green biosynthesis of ZnO nanoparticles by plectranthus amboinicus leaf extract and their application for electrochemical determination of norfloxacin. Inorg. Nano Met. Chem. 2019, 49, 277-282, doi:10.1080/24701556.2019.1661441.

Publisher's Note: MDPI stays neutral with regard to jurisdictional claims in published maps and institutional affiliations.

(C) 2020 by the authors. Submitted for possible open access publication under the terms and conditions of the Creative Commons Attribution (CC BY) license (http://creativecommons.org/licenses/by/4.0/). 